\title{
E3 Ubiquitin-Protein Ligase NEDD4
}

National Cancer Institute

\section{Source}

National Cancer Institute. E3 Ubiquitin-Protein Ligase NEDD4. NCI Thesaurus. Code C68584.

E3 ubiquitin-protein ligase NEDD4 (1000 aa, 115 kDa) is encoded by the human NEDD4 gene. This protein is involved in the transfer of ubiquitin to targ et proteins and may play a role in virion budding from infected cells and tumor suppression. 